\title{
Sink or Collaborate: How the Immersive Model Has Helped Address Typical Adolescent and Young Adult Barriers at a Single Institution and Kept the Adolescent and Young Adult Program Afloat
}

\author{
Damon R. Reed, MD, ${ }^{1,2,5}$ Benjamin Oshrine, MD, Christie Pratt, MA, DHSc, ${ }^{1,2}$ Olivia Fridgen, MPH, \\ Cathy Elstner, RN, ${ }^{1,2}$ Leila Wilson, BSN, RN, ${ }^{1,2}$ Hatem Soliman, MD, Marie C. Lee, MD, Howard L. McLeod, PharmD, \\ Bijal Shah, MD, Kristine A. Donovan, PhD, Smitha Pabbathi, MD, Mary Turney, LCSW, Odion Binitie, MD, \\ Christine Healy, LCSW, Michael Nieder, MD, ${ }^{10}$ Peter H. Shaw, MD, Andrew Galligan, MD,11 \\ G. Douglas Letson, MD, Marilyn Stern, PhD, ${ }^{12,13}$ Gwendolyn P. Quinn, PhD, ${ }^{1,13}$ and Simon Davies, Hon DEd ${ }^{14}$
}

Keywords: AYA oncology, AYA program, model, multidisciplinary collaboration, psychosocial

\section{Introduction}

$\mathbf{T}$ HE UNIQUE NEEDS of adolescent and young adult (AYA) oncology patients have been identified through research and well described in the literature. ${ }^{1-4}$ Defined as individuals aged 15-39 years, these patients benefit from age-appropriate multidisciplinary care with attention to psychosocial, fertility, financial, and physical effects of cancer, from diagnosis through survivorship. These are termed the pillars of AYA care. With the goal of improving outcomes for the 72,000 AYA patients diagnosed with cancer every year in the United States, AYA programs are being developed.

Organizations such as Teen Cancer America (TCA, www .teencanceramerica.org) and Critical Mass (criticalmass.org) provide advocacy, collaboration, and resources for personnel, as well as physical space for AYA patients at major medical centers. Early reports of successful programs have been mitigated more recently by recognition of real barriers to successful program development, prompting an ongoing national dialogue. This article seeks to examine our institution's model and offer solutions to overcome real and perceived barriers to optimal AYA oncology care.

Specifically, we examine our institution's model that involves a pediatric oncologist AYA champion employed within an adult cancer center, which we term the Immersive Model. This differs from other models that typically separate pediatric and adult oncology by building and department or medical group. Traditionally, AYA programs have been created to bridge the gap between pediatric and adult centers, often using acute lymphoblastic leukemia (ALL) care as a model. Pediatric oncologists would expand the age of patients seen upward, to provide direct care or participate in tumor boards with adult medicine colleagues. There is a datadriven consensus in the pediatric oncology community that so-called pediatric-inspired regimens improve outcomes for AYA patients compared with standard adult approaches for ALL and a perception that the medical oncology world has been slow to universally adopt these regimens with variation

\footnotetext{
${ }^{1}$ Adolescent and Young Adult Oncology Program, Moffitt Cancer Center, Tampa, Florida.

${ }^{2}$ Sarcoma Department, Moffitt Cancer Center, Tampa, Florida.

${ }^{3}$ Cancer and Blood Disorders Institute, Johns Hopkins All Children's Hospital, St. Petersburg, Florida.

${ }^{4}$ Breast Oncology, Moffitt Cancer Center, Tampa, Florida.

${ }^{5}$ Department of Individualized Cancer Management, Personalized Medicine Institute, Moffitt Cancer Center, Tampa, Florida.

${ }^{6}$ Malignant Hematology, Moffitt Cancer Center, Tampa, Florida.

${ }^{7}$ Supportive Care Medicine, Moffitt Cancer Center, Tampa, Florida.

${ }^{8}$ Internal Medicine Department and Survivorship Program, Moffitt Cancer Center, Tampa, Florida.

${ }^{9}$ Patient and Family Services, Moffitt Cancer Center, Tampa, Florida.

${ }^{10}$ BMT Program, Moffitt Cancer Center, Tampa, Florida.

${ }_{12}^{11}$ Department of Pediatrics, University of South Florida, Tampa, Florida.

${ }^{12}$ Department of Child and Family Studies, University of South Florida, Tampa, Florida.

${ }^{13}$ Health Outcomes and Behavior Program, Moffitt Cancer Center, Tampa, Florida.

${ }^{14}$ Teen Cancer America, Los Angeles, California.
}

(C) Damon R. Reed et al. 2017; Published by Mary Ann Liebert, Inc. This is an Open Access article distributed under the terms of the Creative Commons Attribution License, which permits unrestricted use, distribution, and reproduction in any medium, provided the original work is properly cited. 
in levels of adoption across centers. ${ }^{5-8}$ Controversy regarding the optimal treatment for ALL continues at many centers, causing AYA program growth to be hindered.

Moffitt Cancer Center (MCC) is a National Cancer Institute-designated Comprehensive Cancer Center based in Tampa, Florida that is uniquely organized by multidisciplinary disease teams rather than the more traditional model of departments of medicine, surgery, and other specialties. Thus, it is common for physicians to report to chairs with different, medical, or surgical, for example, board certifications and training than their own. The AYA program at MCC is led by a pediatric oncologist who reports directly to the chair of the Sarcoma Program, who is a surgical oncologist. MCC does not have a pediatric oncology practice and does not routinely care for patients under 15 years of age, although disease-specific expertise may be provided on a case-by-case basis, with administrative approval.

MCC sees $\sim 16,000$ new patients each year, with over 1500 of these new patients ranging from 15 to 39 years of age. This means that 100-125 unique AYA patients visit MCC each day, and $10 \%$ of inpatient beds are occupied by AYA patients. This volume prompted an administrative decision to contribute hospital resources to AYA patients, with coordinator support. Clinically, the Immersive Model began at
MCC with a pediatric oncologist from All Children's Hospital providing care to sarcoma patients up to 40 years of age with select diagnoses. The program continues to collaborate with Johns Hopkins All Children's Hospital in a variety of ways, including several ongoing research collaborations and multiple physicians with clinical privileges at both facilities. Other groups, bringing broad and necessary expertise, began participating in the program (Fig. 1). MCC has grown to a multidisciplinary AYA Committee that is structured with five subcommittees that focus on: fertility, research, patient education, social events, and psychosocial issues. The entire group meets monthly in an open forum to share communication and discuss opportunities, provide updates on new and ongoing committee initiatives, and review factors that facilitate and obstruct local AYA care.

While adult oncology care centers have clinical expertise regarding several AYA cancer types, such as cutaneous malignancies and carcinomas, it is less common for an AYA program to be established within an adult facility. ${ }^{9}$ We have found that our model has, thus far, largely addressed the common barriers encountered when AYA oncology is shared between pediatric and medical providers or with informal programs. We offer here the results of an interdepartmental discussion to identify barriers and assess our program's model

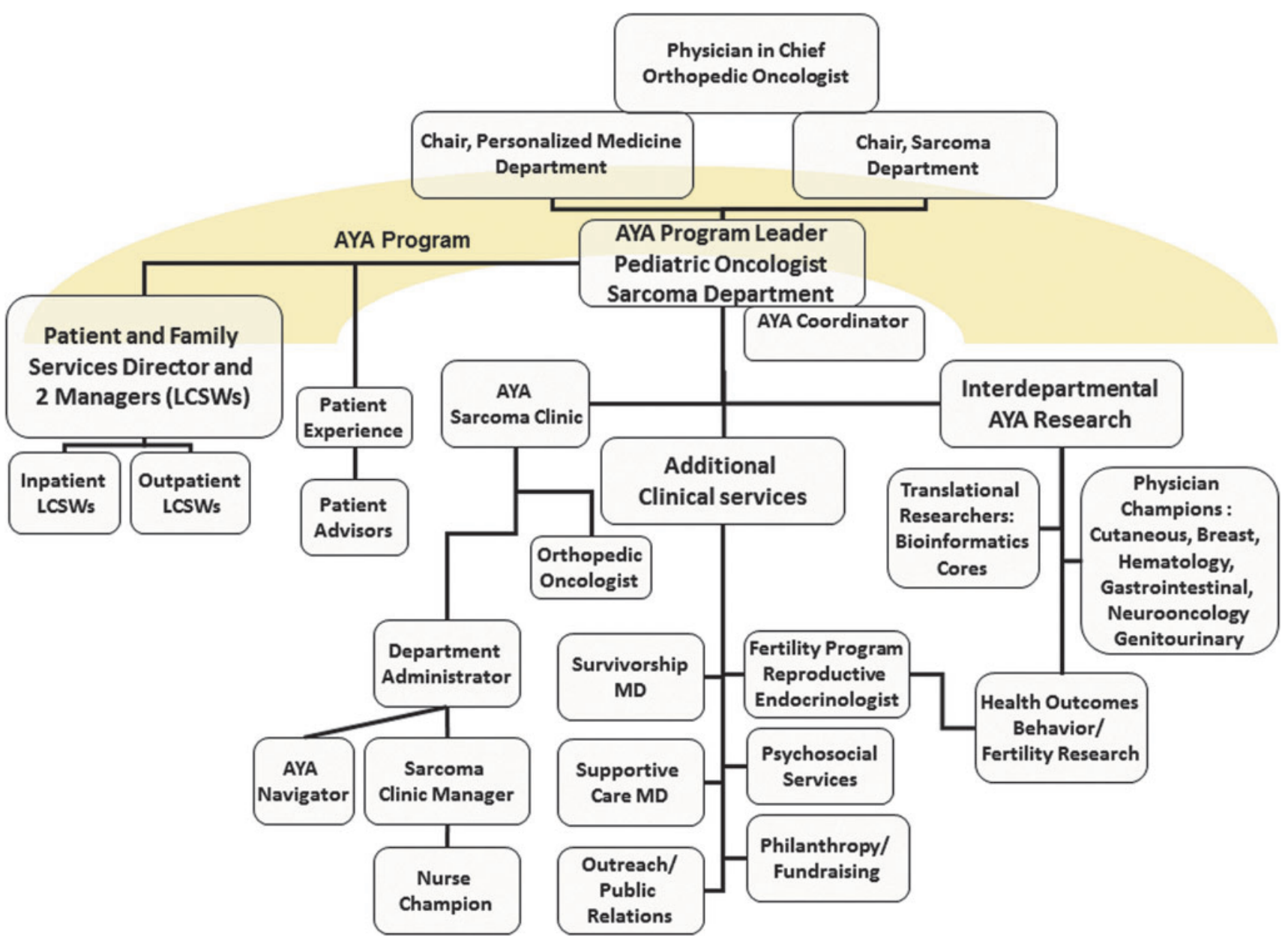

FIG. 1. AYA Program Organizational Chart: The AYA program incorporates many disciplines and areas of expertise together across traditional cancer center departments. AYA, adolescent and young adult. 
in terms of addressing AYA oncology care. We report on how our immersive AYA oncology program has addressed common barriers, real and perceived, that often affect the provision of quality care for AYA patients with cancer.

\section{Barrier 1: Turf War-Medical Oncology Versus Pediatric Oncology}

Lack of time from the medical oncologist due to overwhelming patient care responsibilities is often misperceived by pediatric oncologists as a lack of interest in young adult patients. (Medical oncologist involved in AYA program)

Most clinicians familiar with AYA oncology are aware of the turf war regarding whether pediatric or medical oncologists are better suited to treat AYA patients. It is important to discuss and better understand the perceived and real differences between the disciplines regarding the approach to care, philosophies of care, and expectations of the systems in which pediatric and medical oncologists train and practice, to avoid antagonism and promote collaboration. Typical pediatric oncology programs consist of a relatively small group of physicians who maintain broad expertise in benign hematology and general oncology (Fig. 2A). The average practice will see $\sim 50$ to 80 new oncology patients per year, with over half typically having leukemia or central nervous system malignancies. Because of a successful history of improving outcomes through multi-institutional collaborative clinical trials, care standards are relatively uniform across institutions and typically based on the most recently completed clinical trial results or on active clinical trials. ${ }^{10}$

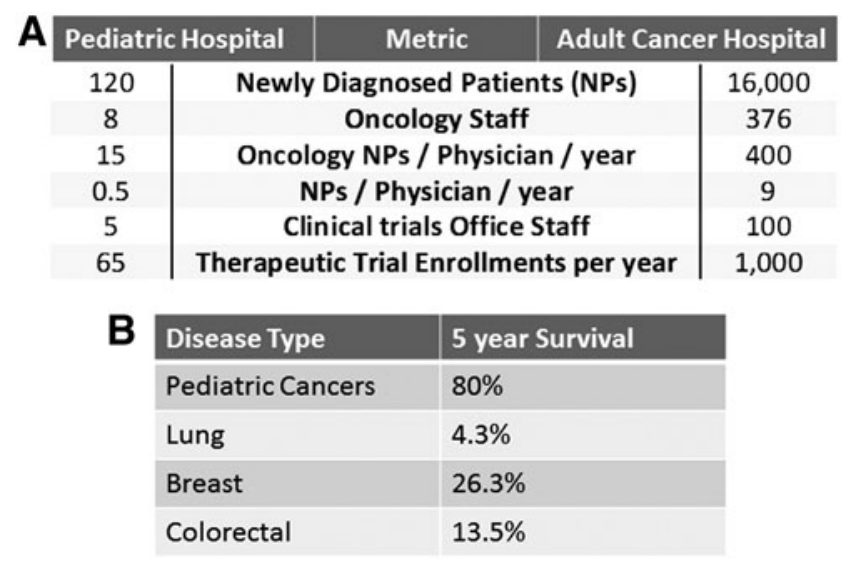

FIG. 2. Barrier 1: Turf War or Differences between Pediatric and Medical Oncology. (A) Approximate numbers of patients, staff, and clinical trial enrollments at MCC and an average pediatric oncology program. (B) Selected outcomes for all pediatric cancers and selected, advanced-stage, highvolume cancer diagnoses seem in the older population. MCC, Moffitt Cancer Center. Source: Surveillance, Epidemiology, and End Results (SEER) program (www.seer.cancer.gov). SEER*Stat Database: Incidence-SEER 18 Regs Research Data+Hurricane Katrina Impacted Louisiana Cases, Nov 2015 Sub (1973-2013 varying), National Cancer Institute, DCCPS, Surveillance Research Program, Surveillance Systems Branch, released April 2016, based on the November 2015 submission. Stage at Presentation: Distant
Acknowledging that the majority of adult patients are cared for in the community rather than Comprehensive Care Centers, we describe the structure at MCC. There is an entrepreneurial spirit endemic to Comprehensive Cancer Centers, which are likely to have adequate patient volumes and lower baseline survival rates that support single-site investigatorinitiated trials, which are frequently prioritized over cooperative group trials (Fig. 2B). In terms of patient volume, medical oncologists have perpetually full schedules, often with waiting lists, in contrast to the limited number of available patients to be seen by typical pediatric oncologists. Generally, $\sim 7 \%$ of the average medical oncologist's 400 new patients seen annually are in the AYA age range (Fig. 2A).

AYA needs may be missed or not prioritized due to the competing demands of the institution and individual physician to increase efficiency, reduce costs, and maintain patient satisfaction. This reality may be perceived by the pediatric community as a lack of understanding and compassion toward the younger population. The AYA oncology provider community knows all too well that these patients require more resources for a given diagnosis for a number of reasons, including, but not limited to, having less knowledge and experience of healthcare, less insurance coverage, and/or greater psychosocial needs. Under the current framework, with a likely worsening trend, the medical oncology community may not be properly equipped to provide the extra time and resources needed for the AYA population. We do not believe that only pediatric oncologists can or should lead AYA programs. Indeed AYA leaders have emerged from multiple disciplines not limited to physicians and thus we do not believe program development necessarily starts with a pediatric oncologist. Within an adult cancer hospital system, the AYA leader should be willing to engage interdisciplinary teams, articulate a vision, and put forth the effort to see projects from inception through completion.

During the preparation of this article, nearly every physician confirmed that differences between a pediatric and medical oncologist's training and schedule volumes were a real and impactful barrier to providing care to AYA patients. Interestingly, nonclinical staff typically viewed these differences as a perceived barrier. This long-standing turf war may not be understood by the whole clinical team and failure to recognize this issue may adversely affect critical clinical decisions. Inability to effectively acknowledge the clinical cultures of pediatric and adult hospitals can hinder effective AYA program building. Shared care of patients across our institutions and venues, such as tumor boards, during which face-to-face discussions routinely occur, have been effective in creating collaborations. There is also discussion around who should be writing clinical trials geared toward improving the enrollment and outcomes of AYA patients. Currently, there are ongoing efforts, models, and trials for this target population. ${ }^{11,12}$

\section{Barrier 2: Limited Resources for an AYA Program}

It feels like I'm back in the college dorm again instead of a hospital room. (AYA patient comment regarding the MCCSwim Across American AYA Lounge)

There are many unmet needs in the AYA population and it can be daunting to try and address all of them when 
developing a program. Thus, AYA programs should be built with goals that are consistent with local expertise and available funds, while aspiring to grow. Other AYA programs have focused, and then reported, on advances of a single pillar of AYA care, such as fertility, ${ }^{13,14}$ psychosocial care, ${ }^{15}$ survivorship, ${ }^{16}$ or trial enrollment. ${ }^{17}$ MCC's AYA Program was built with administrative support through institutional funds and a local philanthropist's commitment and then sustained by additional gifts, ranging from several hundred dollars to over a hundred thousand dollars (Fig. 3A). Importantly, having a single leader for the AYA effort has worked well with regard to patient and program needs, along with setting realistic goals for the use of donated funds. We also ensure timely communication to the donors regarding how the resources are being used. MCC's AYA Program's greatest expense is funding research collaborations (Table 1). These joint research projects are intended to create positive clinical change for AYA patients and have created sustained collaborations with other disease-specific clinicians at the institution.

One particular event that was emblematic of unexpected productive collaborations with external funding sources was the opening of the Swim Across America Adolescent and Young Adult Lounge, built with insight from TCA (Fig. 3B). This physical space was specifically built for and designed by our AYA patients. While intended to improve upon patient's frustrations with inpatient admissions and to have a place between outpatient appointments or during days when needing to get away from the general hustle of a hospital, the lounge has proven to be more than a room. It allows the institution to better communicate the AYA mission. It reduces isolation and provides an organic space for in-patient young adults to meet each other. Many anecdotes of lifelong friendships starting in this space have been shared. Additionally this has provided a better space for patients and our recurring support groups, garnered media attention, and played a role in encouraging philanthropic giving to the AYA Program for additional initiatives.

\section{Barrier 3: Communication and Engagement with AYA Patients, Administration, and Staff}

While initial awareness of AYA issues was limited among MCC staff, several efforts have facilitated broader recognition and understanding of the program within the institution. AYA education is now part of clinical mandatories, provided as continuing education units at grand rounds, highlighted in new staff orientation, and easily found in hospital-wide directories and intranets. Members of the AYA Program regularly present at different department meetings and clinics. Our multidisciplinary AYA Committee is deliberately composed of at least one representative from each area of the hospital, so that there is an AYA champion who is familiar and up to date with AYA-specific initiatives and can serve as
A

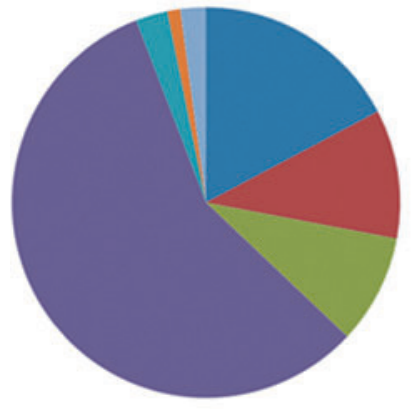

- Lounge, Events

Navigator

- Research - Designated

Research - Unrestricted

- Peer to Peer Support

nertility

Individual Gifts
B

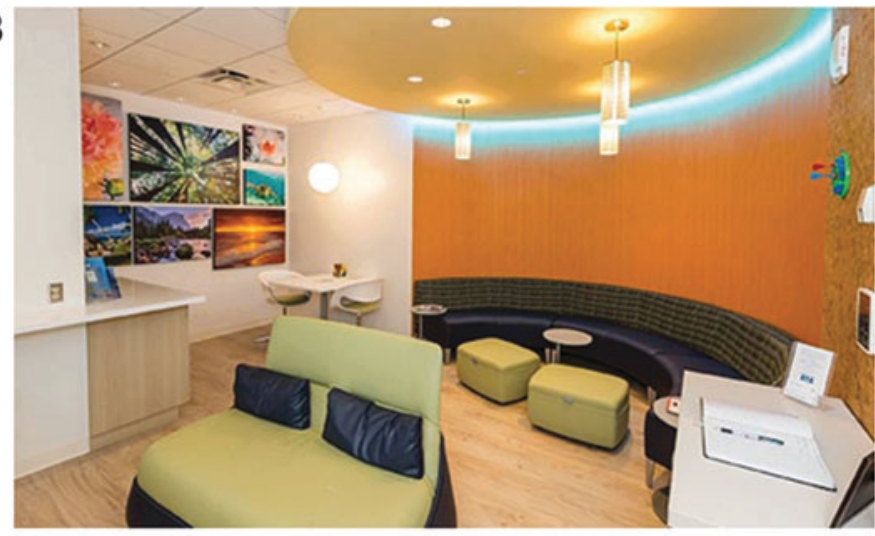

D $100 \%$

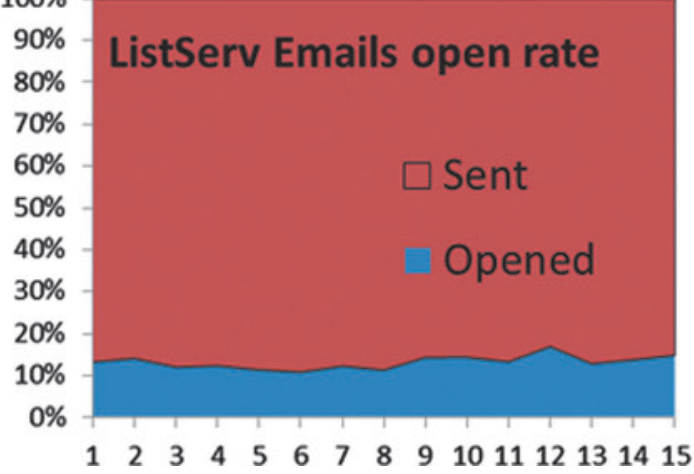

$\begin{array}{llllllllllllllll}1 & 2 & 3 & 4 & 5 & 6 & 7 & 8 & 9 & 10 & 11 & 12 & 13 & 14 & 15\end{array}$
C

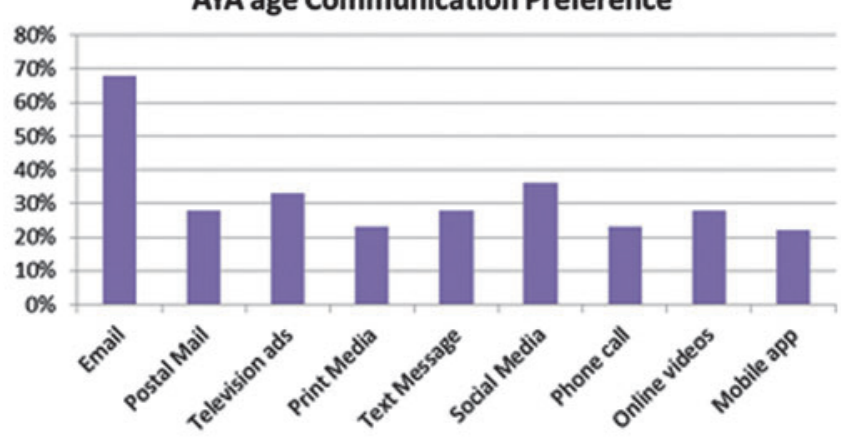

FIG. 3. Barriers 2 and 3: Needed Resources and Communication. (A) Sources of philanthropic funds for MCC AYA program. Additional details about goals of gifts and projects supported in Table 1. (B) MCC Swim Across America AYA Lounge. (C) Patient responses on preferred method of contact. Despite a majority indicating email as the preferred method, (D) opened rates of email remain suboptimal and consistent across serial emails announcing educational or social events. 
Table 1. Adolescent and Young Adult Research and Programmatic Progress Funded FROM GRANTS AND PhILANThropy

\begin{tabular}{|c|c|c|c|}
\hline Source & Period funded & Purpose of funding & Programs/projects funded at MCC \\
\hline $\begin{array}{l}\text { Gonzmart Family Foundation } \\
\text { www.richardsrunforlife.org }\end{array}$ & 2011 to Present & $\begin{array}{l}\text { Research, } \\
\quad \text { unrestricted }\end{array}$ & $\begin{array}{l}\text { - Sarcoma: Osteosarcoma single } \\
\text { institution chemotherapy intensity } \\
\text { AYA and pediatrics }{ }^{21} \\
\text { - Ewing sarcoma disparities }{ }^{22} \\
\text { - Sarcoma/pathology: Ewing sarcoma } \\
\text { biomarkers }{ }^{23,24} \\
\text { - Sarcoma/M2Gen (www.m2gen.com): } \\
\text { Sarcoma endosialin expression }{ }^{25} \\
\text { - HOB: Fertility decision making with } \\
\text { meningioma } \\
\text { - Gastrointestinal oncology: Colorectal } \\
\text { cancers (see Lewis Family Cancer Fund } \\
\text { below) } \\
\text { - HOB: Fertility }{ }^{27} \\
\text { - Cutaneous: AYA trial enrollment, } \\
\text { management of melanoma in younger } \\
\text { patients }{ }^{28-31} \\
\text { - Hematology: AYA outcomes }{ }^{32}\end{array}$ \\
\hline $\begin{array}{l}\text { Swim Across America } \\
\text { www.swimacrossamerica.org }\end{array}$ & 2011 to Present & $\begin{array}{l}\text { AYA lounge and } \\
\text { events }\end{array}$ & $\begin{array}{c}\text { Events, wellness fairs, program building, } \\
\text { quality improvement, }{ }^{2,18,33-36} \text { current } \\
\text { article, AYA pathway development }\end{array}$ \\
\hline $\begin{array}{l}\text { Teen Cancer America } \\
\text { www.teencanceramerica.org }\end{array}$ & 2016 to Present & $\begin{array}{l}\text { Patient navigator } \\
\text { position, AYA } \\
\text { lounge }\end{array}$ & $\begin{array}{l}\text { AYA lounge, current article, AYA health } \\
\text { navigator }(2017-)\end{array}$ \\
\hline $\begin{array}{l}\text { Bay Area Advisors } \\
\text { bayareaadvisors.org }\end{array}$ & 2016 to Present & Research, restricted & $\begin{array}{l}\text { Sarcoma research and survivorship } \\
\text { development }\end{array}$ \\
\hline MCC Internal Grant & 2015 to Present & $\begin{array}{l}\text { Assess patient } \\
\text { navigator position }\end{array}$ & $\begin{array}{l}\text { HOB/supportive care: Distress and } \\
\text { navigation-can a navigator improve } \\
\text { upon current care? }\end{array}$ \\
\hline $\begin{array}{l}\text { Pinellas Partners } \\
\text { moffitt.org/give-back/join/ } \\
\text { pinellas-partners }\end{array}$ & 2016 to Present & $\begin{array}{l}\text { Research, } \\
\text { unrestricted }\end{array}$ & $\begin{array}{l}\text { Survivorship development, osteosarcoma } \\
\text { research }\end{array}$ \\
\hline Ros Miller Jilliansdream.org & 2015 to Present & Peer-to-peer support & $\begin{array}{l}\text { Development of peer-to-peer support for } \\
\text { patients and caregivers }\end{array}$ \\
\hline $\begin{array}{l}\text { Lewis Family Cancer Fund } \\
\text { www.facebook.com/ } \\
\text { LewisFamilyCancerFund }\end{array}$ & 2013 & Research, restricted & $\begin{array}{l}\text { AYA colorectal cancers without } \\
\text { microsatellite instability have different } \\
\text { genetic changes than are found in older } \\
\text { patients with colorectal cancer }\end{array}$ \\
\hline $\begin{array}{l}\text { Cure on Wheels } \\
\text { Cureonwheels.org }\end{array}$ & 2014 to Present & Fertility preservation & $\begin{array}{l}\text { Developed need-based financial support } \\
\text { for male patients with Department of } \\
\text { Social Work. }\end{array}$ \\
\hline
\end{tabular}

AYA, adolescent and young adult; HOB, health outcomes and behavior; MCC, Moffitt Cancer Center.

a liaison. While training of these many disciplines might be thought of as a strain on a nascent AYA program, we have found that the AYA program has instead provided opportunities for nurses to lead and learn from educational talks, and have used AYA quality improvement projects to fulfill requirements for advancement on their clinical ladders. While day-to-day accomplishments can be difficult to articulate, confirmation of the importance of the AYA program has come through special mention of the program during our recent successful Magnet designation, as well as the Cancer Center Support Grant, which both recognized the trans-departmental care teams and research the AYA Program has helped to facilitate. Furthermore, the AYA program has contributed to timely and unanticipated alignment with MCC strategic ini- tiatives, such as providing TCA grant support for a patient navigation initiative along with identifying a pediatric oncologist to direct a growing AYA survivorship program.

Technology use and preferred means of communication vary across the AYA age range. An AYA program needs to add value and be visible to patients and staff. A current barrier at MCC is the inability to create AYA-specific social media accounts. Consequently, this leaves a large gap in information sharing. While the impression is that social media platforms are AYA patients' preferred methods of communicating health information, an informal survey of patients revealed email to be the only communication method preferred by a majority of patients (Fig. 3C). Despite this preference, $<15 \%$ of emails are typically even 
A Important Considerations in Treating Young Adults

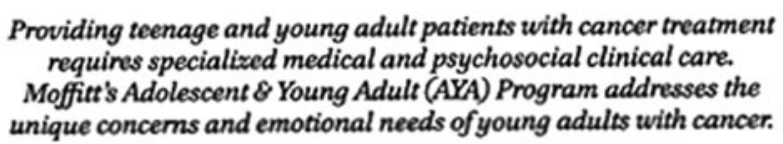

Fertility preservation coordination prior to therapy

Age-appropriate counseling including sexual health and contraception

Pain management, palliative and psychiatric care

Support services specific for young adults

Long term survivorship planning

Regular social and educational opportunities to foster peer relationships
B

\begin{tabular}{|l|c|c|c|}
\hline & $\begin{array}{c}\text { Patients at } \\
\text { Diagnosis }\end{array}$ & $\begin{array}{c}\text { Tumor } \\
\text { Tissue } \\
\text { Sample }\end{array}$ & $\begin{array}{c}\text { Normal } \\
\text { Tissue } \\
\text { (blood or } \\
\text { other) }\end{array}$ \\
\hline Total $<40$ & 17,991 & 1,007 & 19,520 \\
\hline Total $<30$ & 6,549 & 832 & 3,138 \\
\hline
\end{tabular}

Clinical trials information and access

\begin{tabular}{|r|c|c|}
\hline \multicolumn{1}{|c|}{ Date } & Event & $\begin{array}{c}\text { AYA Patient } \\
\text { Attendance }\end{array}$ \\
\hline February 2016 & Social & $20+$ \\
\hline April 2016 & Wellness Fair & $20+$ \\
\hline April 2016 & Social & $10-20$ \\
\hline June 2016 & Social & $10-20$ \\
\hline July 2016 & Social & $10-20$ \\
\hline December 2016 & Social & $20+$ \\
\hline Reoccurring & Social \& Educational & $10-20$ patients each time \\
\hline
\end{tabular}

FIG. 4. Barrier 4: AYA Value. (A) An effort to bring AYA-specific aspects of care to community physician groups is our AYA magnet, which also includes referral information. (B) MCC's ongoing banking efforts have over 1000 tumor samples in AYA patients aged 18-39 and more available normal tissue samples. (C) Attendance ranges at recent events.

opened by our patient population. (Fig. 3D). While we continue to work to improve program communication with patients, we have long recognized the critical importance of connecting fellow AYA patients together. We have reached out through educational and social events, holiday parties, wellness fairs, and community partnerships with consistent attendance (Fig. 4C). We plan to develop a webbased peer-to-peer support application to pilot through a consortium of AYA programs and to connect AYA patients. We intend this to be used for online facilitation of support groups and to reach isolated populations such as bone marrow transplant patients, using their cell phones or other easily accessible devices.

While there are 100 AYA patients seen per day at MCC, they do not crowd the lounge nor do they interact spontaneously. Generally, they prefer to spend as little time in the hospital as possible and are focused on their treatment. A patient's sense of isolation and the clear benefit they could have from meeting other AYA patients or a caring staff member is the largest area of growth potential for the AYA program at MCC. We believe there are numerous missed opportunities to make these connections. While we have many social workers that are enthusiastic about helping
AYA patients, ongoing feedback reflects that optimal use is still a concern. Themes that emerge include the medical teams only involving psychosocial teams with financial or substance abuse problems and likely missing adjustment disorders and other stressors that fall under the clinician's radars for concern, especially if not directly reported by the patient.

Social work also perceives a need to train medical professionals to deal with an inherent discomfort of providing some aspects of care for AYA patients. Improved opportunities for social work to interact with the medical teams and patients at multiple points in time along the cancer journey remain a challenge. To more systematically assess new AYA patients coming to our cancer center, we have collaborated with TCA and hired a patient navigator who performs a telephone assessment before the first visit and alerts social workers in the respective clinics improving chances for an initial psychosocial assessment for all AYA patients. During initial information gathering performed at MCC in preparation for creating the AYA Patient Navigator position, we interviewed AYA patients on and off active treatment and stakeholders across the hospital. It was determined that AYA patients at different points of treatment have different pressing needs. ${ }^{18}$ 
Active therapy patients had unmet immediate day-to-day needs regarding reproductive health assistance, child care, coordination of appointments, feelings of guilt about taking away family and friends' time, and feelings of isolation. Off-therapy patients' expression of unmet needs focused on more global themes, including fear of recurrence, poor communication with the healthcare team, education and employment needs, and the desire to return to normal.

Our medical oncologist providers treating AYAs are generally aware of reproductive health concerns if not the details of generating a referral. Another AYA-specific communication barrier frequently mentioned by our medical group includes the dynamic of adding parents to the physician-patient relationship. Identification of these needs ultimately helped generate a job description and objectives for the AYA Patient Navigator position. We were fortunate that this plan aligned with the cancer center's objectives and goals. We were also able to secure additional grant funding to evaluate this intervention and its effect on AYA patients' experience with the AYA program and overall quality of care.

In the community, we aim to inform providers, patients, and healthy AYA-aged people about AYA oncology. The AYA Program works with physician liaisons and regularly communicates with the physicians who refer AYA patients. MCC's AYA program launched a simple campaign that involved highlighting the "Important Considerations in Treating Young Adults" (Fig. 4A) on a magnet, along with contact information.

\section{Barrier 4: Academic Value in AYA Programs and Research Is Questioned}

Our program aims to discover and implement methods to improve care for AYA patients through research and quality improvement. While some disease-specific departments at MCC are a natural AYA fit based on their epidemiology, AYA oncology is not universally accepted at MCC. AYA oncology can be considered a nonviable academic track for promotions, with limited opportunities for high-impact factor articles. Recognizing this context from the program's inception, plans for broadening the AYA program beyond sarcoma patients have been in place. These included reaching out early and often to department chairs and interested faculty of all experience levels to share our ideas, solicit theirs, and ultimately bring resources and energy to collaborations. We have asked disease-specific AYA questions that could best be answered at out cancer center. An expected and positive aspect of these research-based collaborations has been the identification of AYA champions within other departments. Importantly, this resulting team has sustained our program and led to jointly authored publications (Table 1).

Our Immersive Model creates a unique environment to tackle important clinical questions in the AYA space. We believe that a hospital with an AYA Program will provide better care for AYA patients and that the existence of such a program will entice patients to seek their care at that location. Community oncologists with a better appreciation of the unique needs of this population may be more likely to refer to a Comprehensive Cancer Center with a well-established AYA program. The best currency at MCC is a good scientific question and the resources to answer it. Therefore, our AYA program is built upon MCC's collaborative culture to create teams to answer such questions, and its goals include improving patient care through research, thereby simultaneously creating academic value (Table 1). Ideas to enhance future collaboration include organizing the AYA samples and information from a larger cancer database, the Oncology Research Information Exchange Network (oriencancer.org) (Fig. 4B).

\section{The Pillars of Care: AYA Patients Are Unique}

Having discussed how the immersive model functions at our center to address traditional barriers, we turn to "the pillars," which are essential elements in an AYA program, and discuss them within the model. AYA oncology is inherently multidisciplinary, with the pillars of care traditionally associated with AYA program goals, including psychosocial support, clinical care, clinical trials, financial counseling, fertility counseling and preservation, research, education, and survivorship. For context, the Health Care Rights Initiative previously launched a Centers of Excellence Program named Change it Back, as a way to structure AYA programs on a national scale, but it is no longer active (hcri.org/programs/change-it-back). To qualify as a Center of Excellence, each program was to contain certain key elements, to include fertility counseling, health insurance and financial counseling, clinical trial education and facilitation, psychosocial support, and transition to surveillance and survivorship services. At MCC, our AYA committee is multidisciplinary and meets on a monthly basis with at least one member from each pillar, with the addition of genetics, advocacy and community outreach, legal aid and vocation assistance, contraception and sexual health, and political lobbying. While some of these components may fall under the larger umbrella of existing pillars, others may be better addressed by national AYA efforts, such as Critical Mass or the Alliance for Fertility Preservation.

In accordance with guidelines from national cancer organizations, individual institutions are required to provide this type of care to all AYA patients; however, many programs have emphasized a subset of these pillars, developing expertise and focus that can serve as a paradigm for others. We have several near-term goals that include (1) building a regional AYA survivorship program that will transcend traditional hospital referral barriers by involving three regional pediatric oncology programs, (2) identifying research opportunities across disease specialties within the cancer center, (3) continuing to champion fertility education, research, and advocacy, and (4) raising money to support and sustain collaborative research through grants and philanthropy.

Even when survivors receive long-term monitoring, there is evidence that AYAs are ineffectively assisted or underserved by available support services. ${ }^{1,19}$ The National Cancer Institute's AYA Health Outcomes and Patient Experience study showed that over one third of AYA survivors reported at least one unmet service need. ${ }^{20}$ Survivors with unmet needs were found to have worse overall health-related quality of life. ${ }^{20}$ Thus, while many of the survivorship issues common to AYAs are similar to those of other age groups, specific AYAcentric needs should be addressed. The survivorship pillar is actively being addressed at MCC with the establishment of an AYA-specific survivorship clinic staffed by a pediatric oncologist from a collaborating institution. 


\section{Conclusion}

The Immersive Model, embedding a pediatric oncologist in an adult oncology setting, helps overcome typical barriers that can hinder AYA Program development. Importantly, at MCC we enjoy strong administrative support, have a collaborative multidisciplinary AYA Committee, maintain financial support from the community, and have built a culture of team science championed by the AYA program leader. We hope the Immersive Model can aid other cancer centers in trying to improve the multidisciplinary care needed to improve outcomes and quality of care for this unique patient population.

\section{Acknowledgments}

The authors thank the many organizations listed in Table 1 along with the individual donors that have provided energy and resources to the AYA program at MCC. The authors also thank Sonya Smyk (MCC) for her editorial review.

\section{Author Disclosure Statement}

No competing financial interests exist.

\section{References}

1. Zebrack BJ, Block R, Hayes-Lattin B, et al. Psychosocial service use and unmet need among recently diagnosed adolescent and young adult cancer patients. Cancer. 2013; 119(1):201-4.

2. Murphy D, Klosky JL, Reed DR, et al. The importance of assessing priorities of reproductive health concerns among adolescent and young adult patients with cancer. Cancer. 2015;121(15):2529-36.

3. Bleyer A, Montello M, Budd T, Saxman S. National survival trends of young adults with sarcoma: lack of progress is associated with lack of clinical trial participation. Cancer. 2005;103(9):1891-7.

4. Bleyer AW, Barr RD, Albritton KH, Phillips M, Siegel S (Eds). Cancer in Adolescents and Young Adults. Berlin: Springer Verlag; 2007; pp. 83-98.

5. Isakoff MS, Freyer DR, Bleyer A. Young adults with acute lymphoblastic leukemia treated with a pediatric-inspired regimen do not need a bone marrow transplant in first remission. Blood. 2013;121(26):5253-5.

6. Gupta V, Richards S, Rowe JM. Response: chemotherapy versus allogeneic transplantation in adult patients with acute lymphoblastic leukemia in first remission-not a time for dogma. Blood. 2013;121(26):5255.

7. Ram R, Wolach O, Vidal L, et al. Adolescents and young adults with acute lymphoblastic leukemia have a better outcome when treated with pediatric-inspired regimens: systematic review and meta-analysis. Am J Hematol. 2012;87(5):472-8.

8. Schafer ES, Hunger SP. Optimal therapy for acute lymphoblastic leukemia in adolescents and young adults. Nat Rev Clin Oncol. 2011;8(7):417-24.

9. Reed D, Block RG, Johnson R. Creating an adolescent and young adult cancer program: lessons learned from pediatric and adult oncology practice bases. J Natl Compr Canc Netw. 2014;12(10):1409-15.

10. Adamson PC. The Children's Oncology Group's 2013 five year blueprint for research. Pediatr Blood Cancer. 2013; 60(6):955-6.

11. Weiss AR, Hayes-Lattin B, Kutny MA, et al. Inclusion of adolescents and young adults in cancer clinical trials. Semin Oncol Nurs. 2015;31(3):197-205.
12. Weiss AR, Nichols CR, Freyer DR. Enhancing adolescent and young adult oncology research within the National Clinical Trials Network: rationale, progress, and emerging strategies. Semin Oncol. 2015;42(5): 740-7.

13. Woodruff TK. The Oncofertility Consortium-addressing fertility in young people with cancer. Nat Rev Clin Oncol. 2010;7(8):466-75.

14. Levine J, Canada A, Stern CJ. Fertility preservation in adolescents and young adults with cancer. J Clin Oncol. 2010;28(32):4831-41.

15. Daniel CL, Emmons KM, Fasciano K, et al. Needs and lifestyle challenges of adolescents and young adults with cancer: summary of an Institute of Medicine and Livestrong Foundation Workshop. Clin J Oncol Nurs. 2015; 19(6):675-81.

16. Freyer DR. Transition of care for young adult survivors of childhood and adolescent cancer: rationale and approaches. J Clin Oncol. 2010;28(32):4810-8.

17. Downs-Canner S, Shaw PH. A comparison of clinical trial enrollment between adolescent and young adult (AYA) oncology patients treated at affiliated adult and pediatric oncology centers. J Pediatr Hematol Oncol. 2009;31(12):927-9.

18. LaRosa KN, Stern M, Bleck J, et al. Adolescent and young adult patients with cancer: perceptions of care. J Adolesc Young Adult Oncol. 2017 [Epub ahead of print]; DOI: 10.1089/jayao.2017.0012.

19. Zebrack B, Hamilton R, Smith AW. Psychosocial outcomes and service use among young adults with cancer. Semin Oncol. 2009;36(5):468-77.

20. Smith AW, Parsons HM, Kent EE, et al. Unmet support service needs and health-related quality of life among adolescents and young adults with cancer: the AYA HOPE study. Front Oncol. 2013;3:75.

21. Haddox CL, Han G, Anijar L, et al. Osteosarcoma in pediatric patients and young adults: a single institution retrospective review of presentation, therapy, and outcome. Sarcoma. 2014; 2014:402509.

22. Koohbanani B, Han G, Reed D, et al. Ethnicity and age disparities in Ewing sarcoma outcome. Fetal Pediatr Pathol. 2013;32(4):246-52.

23. Bui MM, Han G, Acs G, et al. Connexin 43 is a potential prognostic biomarker for ewing sarcoma/primitive neuroectodermal tumor. Sarcoma. 2011;2011:971050.

24. Shukla N, Schiffman J, Reed D, et al. Biomarkers in Ewing sarcoma: the promise and challenge of personalized medicine. A report from the Children's Oncology Group. Front Oncol. 2013;3:141.

25. O'Shannessy DJ, Dai H, Mitchell M, et al. Endosialin and associated protein expression in soft tissue sarcomas: a potential target for anti-endosialin therapeutic strategies. Sarcoma. 2016;2016:5213628.

26. Owens MA, Craig BM, Egan KM, Reed DR. Birth desires and intentions of women diagnosed with a meningioma. J Neurosurg. 2015:122(5):1151-6.

27. Quinn GP, Block RG, Clayman ML, et al. If you did not document it, it did not happen: rates of documentation of discussion of infertility risk in adolescent and young adult oncology patients' medical records. J Oncol Pract. 2015;11(2): 137-44.

28. Dale Han LMT, Reed DR, Messina JL, Sondak VK. The prognostic significance of lymph node metastasis in pediatric melanoma and atypical melanocytic proliferations. Expert Rev Dermatol. 2013;8(2):103-6. 
29. Han D, Zager JS, Han G, et al. The unique clinical characteristics of melanoma diagnosed in children. Ann Surg Oncol. 2012;19(12):3888-95.

30. Sreeraman Kumar R, Messina JL, Reed D, et al. Pediatric melanoma and atypical melanocytic neoplasms. Cancer Treat Res. 2016;167:331-69.

31. Sreeraman-Kumar R, Messina JL, Sondak VK, Reed DR. Treating melanoma in adolescents and young adults: challenges and solutions. Clin Oncol Adolesc Young Adults. 2015;2015(5):75-86.

32. Grabska J, Shah B, Reed D, et al. Myelodysplastic syndromes in adolescent young adults: one institution's experience. Clin Lymphoma Myeloma Leuk. 2016;16 Suppl: S53-6.

33. Fridgen O, Sehovic I, Bowman ML, et al. Contraception: the need for expansion of counsel in adolescent and young adult (AYA) cancer care. J Cancer Educ. 2016 [Epub ahead of print]; DOI: 10.1007/s13187-016-1003-8.

34. Isenalumhe LL, Fridgen O, Beaupin LK, et al. Disparities in adolescents and young adults with cancer. Cancer Control. 2016;23(4):424-33.
35. Quinn GP, Goncalves V, Sehovic I, et al. Quality of life in adolescent and young adult cancer patients: a systematic review of the literature. Patient Relat Outcome Meas. 2015; 6:19-51.

36. Shaw PH, Reed DR, Yeager N, et al. Adolescent and young adult (AYA) oncology in the United States: a specialty in its late adolescence. J Pediatr Hematol Oncol. 2015;37(3): 161-9.

37. Kothari N, Teer JK, Abbott AM, et al. Increased incidence of FBXW7 and POLE proofreading domain mutations in young adult colorectal cancers. Cancer. 2016;122(18): 2828-35.

Address correspondence to:

Damon R. Reed, MD

Moffitt Cancer Center

FOB-1, Sarcoma Department 12902 Magnolia Drive

Tampa, FL 33612

Email: damon.reed@moffitt.org 